Article

\title{
In Search of Governing Gas Flow Mechanism through Metal Solid Foams
}

\author{
Anna Gancarczyk ${ }^{1, *}$, Marcin Piątek ${ }^{1}$, Marzena Iwaniszyn ${ }^{1}$, Przemysław J. Jodłowski ${ }^{2}$, \\ Joanna Lojewska ${ }^{3}$, Jolanta Kowalska ${ }^{4}$ and Andrzej Kołodziej ${ }^{1,4}$ \\ 1 Institute of Chemical Engineering, Polish Academy of Sciences, Bałtycka 5, 44-100 Gliwice, Poland; \\ mpiatek@iich.gliwice.pl (M.P.); miwaniszyn@iich.gliwice.pl (M.I.); ask@iich.gliwice.pl (A.K.) \\ 2 Faculty of Chemical Engineering and Technology, Cracow University of Technology, Warszawska 24, \\ 31-155 Kraków, Poland; jodlowski@chemia.pk.edu.pl \\ 3 Department of Chemistry, Jagiellonian University, Ingardena 3, 30-060 Kraków, Poland; \\ joanna.lojewska@uj.edu.pl \\ 4 Faculty of Civil Engineering and Architecture, Opole University of Technology, Katowicka 48, \\ 45-061 Opole, Poland; j.kowalska@po.opole.pl \\ * Correspondence: anna.g@iich.gliwice.pl; Tel.: +48-32-234-6915
}

Academic Editors: Luis M. Gandía, Mario Montes and José Antonio Odriozola Received: 9 February 2017; Accepted: 17 April 2017; Published: 21 April 2017

\begin{abstract}
Solid foams have been intensely studied as promising structured catalytic internals. However, mechanisms governing flow and transport phenomena within the foam structures have not been properly addressed in the literature. The aim of this study was to consider such flow mechanisms based on our experimental results on flow resistance. Two mechanisms were considered: developing laminar flow in a short capillary channel (flow-through model), and flow around an immersed solid body, either a cylinder or sphere (flow-around model). Flow resistance experiments were performed on three aluminum foams of 10, 20, and 40 PPI (pores per inch), using a $57 \mathrm{~mm}$ ID test column filled with the foams studied. The foam morphology was examined using microtomography and optical microscopy to derive the geometric parameters applied in the model equations. The flow-through model provided an accuracy of $25 \%$ for the experiments. The model channel diameter was the foam cell diameter, and the channel length was the strut thickness. The accuracy of the flow-around model was only slightly worse (35\%). It was difficult to establish the geometry of the immersed solid body (sphere or cylinder) because experiment characteristics tended to change from sphere to cylinder with increasing PPI value.
\end{abstract}

Keywords: open-cell foams; flow resistance; flow modelling; foam morphology

\section{Introduction}

Despite important advantages such as easy catalyst replacement, low cost, and satisfactory transfer properties, traditional packed bed (dumped bed) reactors used in the chemical industry exhibit the main drawback of high flow resistance due to a small void fraction [1]. This problem is overcome by ceramic monoliths, exhibiting low flow resistance through long, straight capillary channels, but, the heat/mass transfer rate is often too low, especially for fast catalytic reactions.

Nowadays, open-cellular metal foams have been seriously considered and widely studied as a promising intermediate solution between the monolith and packed bed. We previously discussed the possibility of using this catalyst support for $\mathrm{NO}_{x}$ catalytic reduction with ammonia [2]. The foams have many potential benefits, including reasonably low flow resistance, intense heat/mass transfer properties, large specific surface area, and extremely high porosity, exceeding $90 \%$. However, the morphological characterization of foams remains a big problem. 
There are numerous methods of solid foam characterization, e.g., X-ray computer tomography (CT) [3-5], magnetic resonance imaging (MRI) [6], or microscopic methods [3,7]. The foam geometry can be modeled as a regular structure based on theoretical models like the cubic cell or Kelvin cell (for details see [5]) or as a real structure based on the CT reconstruction of real foam scans. One of the methods of foam geometry reconstruction is the use of algorithms based on Voronoi tessellations (e.g., [8]).

To describe the complex spatial structure of solid foams, numerous morphological parameters such as cell, window, node, and strut diameter (Figure 1), tortuosity factor, specific surface area, and porosity can be defined. However, the dimensions of all the foam elements undergo a statistical distribution. The potential to manufacture foam from various materials (such as metals, ceramics, glass, carbon, polymers etc.) is undoubtedly advantageous, but the foam morphology strongly depends on the material and manufacturing technology applied. In fact, the foam geometry determines the flow (and transfer) characteristics. For instance, in addition to the material and technology applied, the cross-sectional shape of the foam struts is connected with the porosity [9]. Moreover, the foam skeleton can be solid or porous, with the pores either open or closed to the foam void space $[10,11]$.

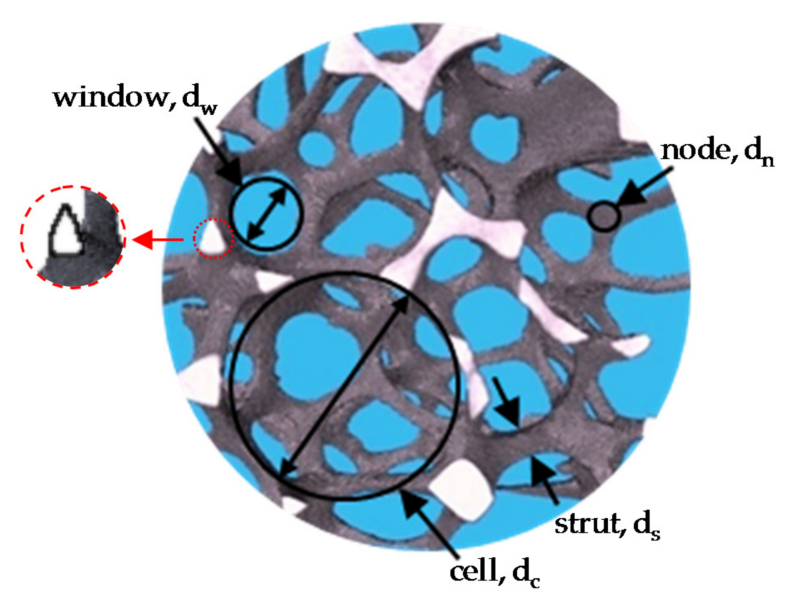

Figure 1. Tomographic reconstruction of the Al 20 PPI (pores per inch) foam with characteristic elements. The strut cross section is shown on a larger scale.

Many correlations describing the flow resistance $(\Delta P / H)$ for different solid foams exist in the literature (e.g., [1,11-14]). However, most display serious divergences upon comparison (see e.g., Dietrich [14]). The reason could be, as the author suggests, some problems with the correct determination of the specific surface area or the morphological parameters describing the foam skeleton. Moreover, correlations presented in the literature are based mainly on experiments performed for a single foam or a very limited set of them. Therefore, it is not surprising that the literature correlations can only describe some foams accurately, while failing for others, which means the literature correlations cannot be applied indiscriminately. As the foam morphology has a great influence on flow resistance [15], it is recommended that special attention is paid to checking the conformity of the considered foam morphology to that reported in the literature.

Despite the many correlations presented in the literature, the problem of governing flow mechanism through solid foams has not been discussed sufficiently. An understanding of the fluid flow mechanism within the foam structure is necessary for a proper description of the chemical reaction and heat, the mass and momentum transfer, and thus for enhanced modelling of, for example, the catalytic processes using solid foams.

Therefore, the aim of the study was to discuss the mechanism of gas flow through a complex foam structure. Visually, metal foam consists of many small struts jointed together into a spatial structure. 
This may suggest flow around a submerged solid body (i.e., strut) as the governing flow mechanism (flow-around). However, the struts divide the foam space into cells interconnected via windows. The cells and windows can be regarded as very short capillaries where the laminar developing flow occurs, suggesting the flow through short capillary channels (flow-through model). The diameter of the model channel seems to be close to that of the cell or window while the channel length, where the laminar flow develops, might be the cell dimension or the strut thickness. Therefore, both the models, i.e., flow-around and flow-through, were analyzed and are discussed in the article to determine the correct flow mechanism through solid foams based on the collected experimental database of pressure

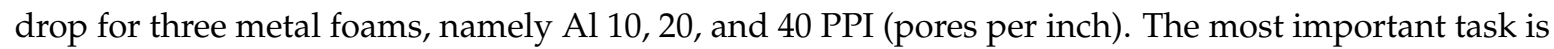
to find the connection between the foam morphology and the description of the flow mechanism.

Though experimentally derived literature correlations do not generally consider the flow mechanism, it is usually present only implicit in the correlation equations. When a dimension representing a channel diameter (e.g., hydraulic diameter in Schlegel et al. [16]) appears in the Reynolds number, the flow-through model is assumed while the strut diameter in the Reynolds number (e.g., Giani et al. [11]) suggests the flow-around model.

\section{Results}

\subsection{Pressure Drop Measurement}

Experimental flow resistance results $(\Delta P / H)$ for the $\mathrm{Al} 10$ and $\mathrm{Al} 40$ foams are presented in Figure 2, together with some literature correlations. It is clear that the literature results cannot predict the flow behavior for all foams with acceptable accuracy. The equations differ greatly, thus producing significant scatter: while for one foam the model prediction is acceptable, (e.g., Inayat et al. [12] describes the Al 40 PPI foam satisfactorily (Figure 2b)), it fails for other foams, as shown in Figure 2a for the Al 10 PPI foam. It is probably, as suggested also by Dietrich [14], connected with the proper determination of the specific surface area and other morphological parameters of the solid foams. Moreover, some correlations use the term $(1-\varepsilon)$ (e.g., [13]): as the porosity of the solid foams is very high, even up to $97 \%$, the expression $(1-\varepsilon)$ can give a very low value. Thus, despite the rather small variations of the solid foam porosities resulting from various experimental techniques, the derived pressure drop value can be altered by even small inaccuracies in the porosity determination. The other problem is the proper determination of the cross-sectional shape of the strut. This shape determines the constant value in the correlation proposed by Inayat et al. [12]. Taking into account the porosity for Al 20 PPI foam (0.91), according to the authors [12], it should have a circular cross section of the strut (for $\varepsilon<0.92-0.93$ ), but it is rather close to a triangle (compare the strut cross section shown in Figure 1).

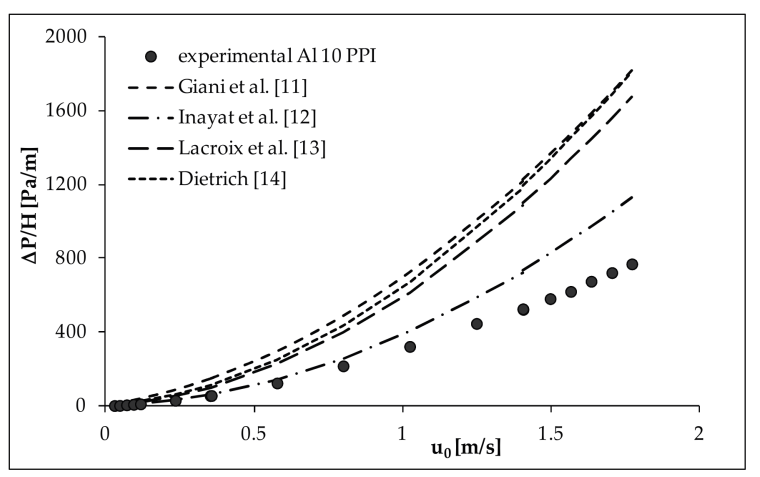

(a)

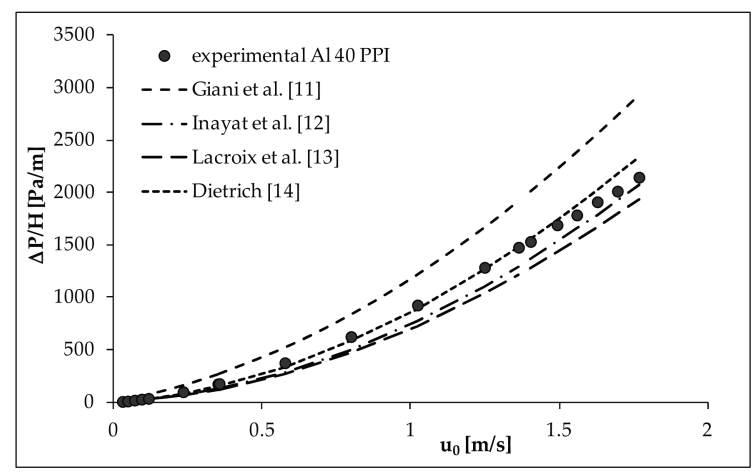

(b)

Figure 2. Flow resistance for $\mathrm{Al} 10 \mathrm{PPI}$ (a) and $\mathrm{Al} 40$ PPI (b) foams: experimental results compared with selected literature correlations. 
Therefore, the literature correlations do not suit all the experimental results well enough, although a detailed selected literature equation might approach the experimental results for foam examined with acceptable accuracy.

\subsection{Pressure Drop Modelling}

Considering the fluid flow through any porous medium, two essential assumptions can be applied for modelling, namely flow-through a capillary and flow-around a solid body (a sphere or a cylinder). These approaches were successfully applied in the literature for other reactor fillings: flow around a sphere-e.g., pneumatic transport and sedimentation of grains $[17,18]$, flow around a cylinder-e.g., fluid flow through woven screens [19], and flow through a short capillary duct-e.g., for very short monoliths [20].

Let us consider the foam structure (cf. Figure 1). For the flow-through mechanism, different ideas of channels can be considered and the model channel diameter $D$ can be the cell, window, pore or even the hydraulic diameter, while the channel length $L$ can be represented by the dimension of the cell, the pore or the strut thickness. It is difficult to settle which dimensions would be correct: the foam structure is complex and stochastic, thus different situations can occur during the fluid flow. Therefore, all of them should be regarded during the model formulation. What is more, all of the suggestions mentioned above can be regarded as very short channels where the laminar flow cannot fully develop (cf. dimensions in Table 1). Therefore, solutions for the Fanning friction factor $f$ in developing laminar flow should be used [21,22]. The experimentally derived Fanning friction factor $f$ is defined by the Darcy-Weisbach equation:

$$
\frac{\Delta P}{H}=2 f \frac{\rho u_{0}^{2}}{\varepsilon^{2} D}
$$

where $\rho$ is the gas density $\left(\mathrm{kg} / \mathrm{m}^{3}\right), u_{0}$ is the superficial gas velocity $(\mathrm{m} / \mathrm{s}), \varepsilon$ is the foam porosity, $D$ is assumed channel diameter $(\mathrm{m})$ and $H$ is the foam bed height $(\mathrm{m})$. The following variants of the model channel diameter $D$ may be considered:

- $\quad$ the average cell diameter, $d_{\mathrm{c}}$

- the average window diameter, $d_{\mathrm{w}}$

- $\quad$ the average pore diameter, $d_{\mathrm{p}}$ (i.e., both cell and window diameter)

- the hydraulic diameter, $d_{\mathrm{h}}=4 \varepsilon / S_{\mathrm{v}}$

The possible model channel length $L$ can be:

- $\quad$ the average cell diameter, $d_{\mathrm{c}}$

- the average pore diameter, $d_{\mathrm{p}}$

- $\quad$ the average strut diameter (thickness), $d_{\mathrm{s}}$

Table 1. Morphological parameters of the foams studied.

\begin{tabular}{ccccccc}
\hline Foam & $\begin{array}{c}\text { Pore Diameter, } \\
\boldsymbol{d}_{\mathbf{p}}(\mathbf{m m})\end{array}$ & $\begin{array}{c}\text { Cell Diameter, } \\
\boldsymbol{d}_{\mathbf{c}}(\mathbf{m m})\end{array}$ & $\begin{array}{c}\text { Window Diameter, } \\
\boldsymbol{d}_{\mathbf{w}}(\mathbf{m m})\end{array}$ & $\begin{array}{c}\text { Strut Diameter, } \\
\boldsymbol{d}_{\mathbf{s}}(\mathbf{m m})\end{array}$ & $\begin{array}{c}\text { Porosity, } \boldsymbol{\varepsilon} \\
\text { Specific Surface } \\
\mathbf{A r e a}_{\mathbf{v}} \boldsymbol{S}_{\mathbf{v}}\left(\mathbf{m}^{\mathbf{2}} / \mathbf{m}^{\mathbf{3}}\right)\end{array}$ \\
\hline Al 10 PPI & 2.48 & 4.73 & 1.90 & 0.45 & 0.89 & 861 \\
Al 20 PPI & 2.02 & 4.04 & 1.74 & 0.37 & 0.91 & 927 \\
Al 40 PPI & 1.70 & 2.58 & 0.92 & 0.30 & 0.91 & 1140 \\
\hline
\end{tabular}

The friction factor $f$ can be calculated using the theoretical equation derived by Shah and London [22] for a circular duct:

$$
f=\frac{3.44}{\operatorname{Re}\left(L^{+}\right)^{1 / 2}}+\frac{16+1.25 /\left(4 L^{+}\right)-3.44\left(L^{+}\right)^{-1 / 2}}{\operatorname{Re}\left(1+0.00021\left(L^{+}\right)^{-2}\right)}
$$


where dimensionless channel length $L^{+}$is defined as $L^{+}=L /(D R e)$ and $R e=\left(u_{0} D \rho\right) /(\varepsilon \eta) ; L$ is the model channel length $(\mathrm{m})$ and $\eta$ is gas viscosity $(\mathrm{Pa} \cdot \mathrm{s})[21,22]$. A similar approach was successfully applied, for example, for the wire gauzes [23].

All the above variants were considered. The assumed channel diameter $D$ in Equation (1) (to calculate Fanning friction factors $f$ from experimental $\Delta P / H$ data) was always in accordance with those applied in Equation (2) (i.e., in the formulae for $L^{+}$and $R e$ ) to calculate the model-based friction factors. The results are presented in Figure 3 for $\mathrm{Al} 40$ foam; for other foams studied the outcomes were similar.

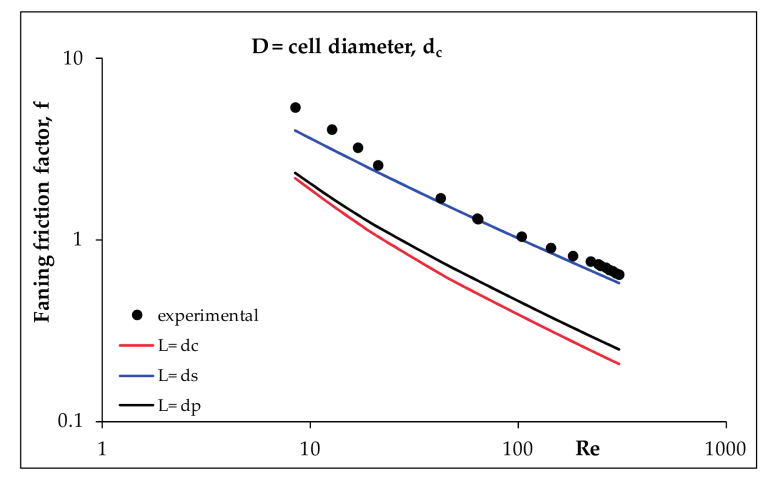

(a)

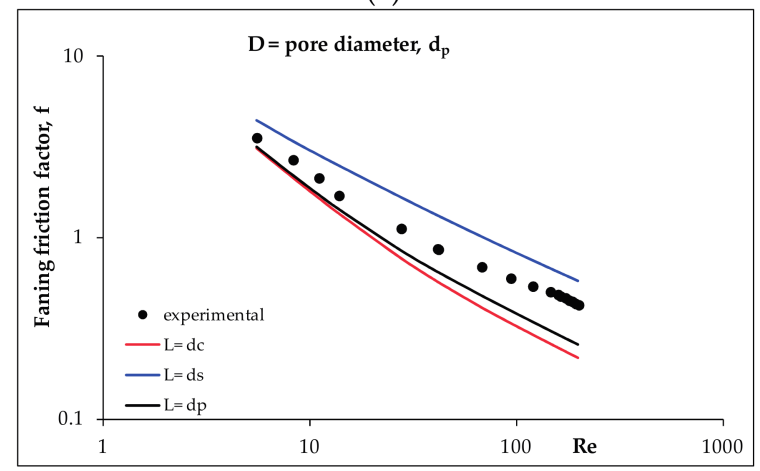

(c)

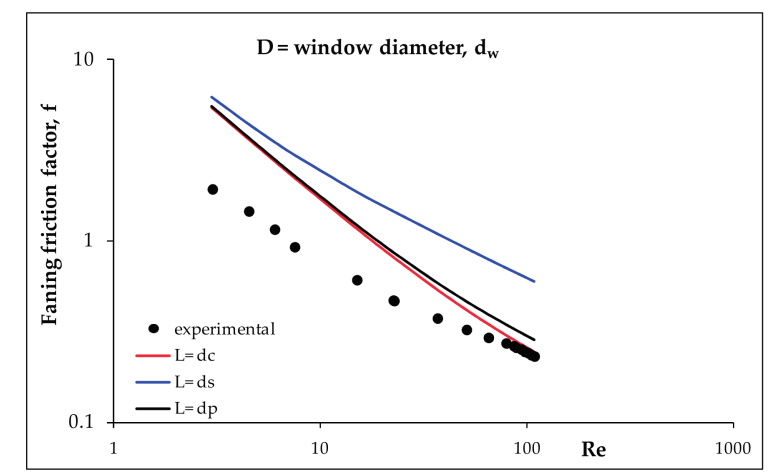

(b)

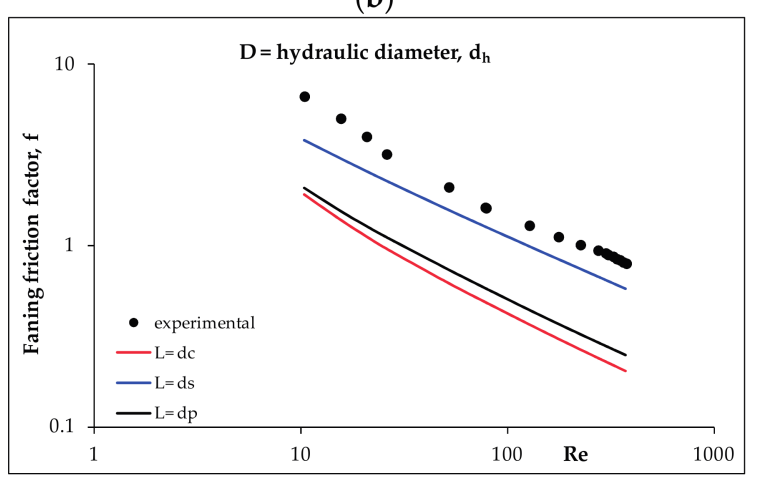

(d)

Figure 3. Comparison of experimentally derived Fanning friction factor $f$ with different model lengths $L$ and channel diameters $D$ defined as: (a) cell diameter; (b) window diameter; (c) pore diameter; (d) hydraulic diameter; for Al 40 PPI metal foam.

The best conformity between modelling and experiments was found for the model presented in Figure 3a: $D=d_{\mathrm{c}}$ (cell diameter) and $L=d_{\mathrm{s}}$ (strut diameter). The same conclusion was found for the Al 10 PPI and Al 20 PPI foams. Other approaches yielded greater deviations from the experiments. Summarizing, the pressure drop has to be calculated using Equation (1) with the Fanning friction factor $f$ derived from Equation (2). For all the foams studied, the flow-through model resulted in an average error $e_{Y} \approx 25 \%$.

For the flow-around approach, two types of geometry are commonly considered in the literature, namely an infinite cylinder and a sphere. When looking at the foam structure (Figure 1), the flow around cylinder can be a model of flow around the foam strut. Obviously, the struts are rather short and usually triangular or similar in cross section rather than circular. Flow around a sphere might represent the flow around the foam node. However, the nodes are rather irregular and their dimensions are difficult to define. On the other hand, the node dimension is proportional to the strut thickness. Therefore, in both cases (i.e., flow around a cylinder and a sphere) the strut diameter is assumed as the 
characteristic dimension, with some simplification taken into consideration. The drag coefficient $C_{\mathrm{D}}$ is defined as (see Appendix A):

$$
\frac{\Delta P}{H}=\frac{C_{\mathrm{D}} \rho u_{0} S_{\mathrm{V}}}{2 \pi \varepsilon^{2}}
$$

In the literature many authors developed correlations for the drag coefficient $C_{\mathrm{D}}$ for a sphere (see e.g., [17]), but the results do not differ significantly. In this study, the correlation of Torobin and Gauvin [18] was chosen:

$$
C_{\mathrm{D}}=\frac{24}{R e_{\mathrm{s}}}\left(1+0.197 R e_{\mathrm{s}}^{0.63}+0.0026 R e_{\mathrm{s}}^{1.38}\right)
$$

where $R e_{\mathrm{s}}$ is the Reynolds number calculated with the strut diameter, $d_{\mathrm{s}}$. For a cylinder, the experimental data of drag coefficient $C_{\mathrm{D}}$ presented by Tong and London [19] were applied.

Drag coefficients $C_{\mathrm{D}}$ have been derived from our experimental data according to Equation (3) for all the foams studied and presented in Figure 4 vs. $R e_{\mathrm{s}}$ number. In Figure 4 , the dependencies for a sphere by Torobin and Gauvin [18] and the data for an infinite cylinder by Tong and London [19] are also shown.

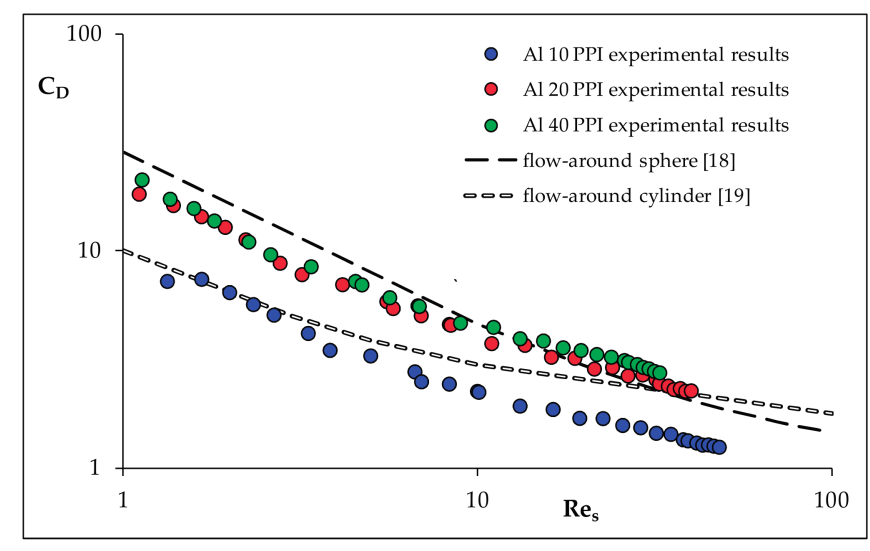

Figure 4. The flow-around model in terms of the experimental drag coefficients $C_{D}$ vs. Reynolds number $R e_{\mathrm{s}}$ compared with drag coefficients for a sphere [18] and infinite cylinder [19].

According to Figure 4, the drag coefficients increase with the PPI value of the foam: the Al 10 PPI foam reflects the cylinder dependence, while Al 20 PPI and Al 40 PPI are situated nearby the sphere drag coefficient. This means that the drag coefficient increases with the PPI and $S_{\mathrm{v}}$ values, and decreases with the $d_{\mathrm{p}}, d_{\mathrm{w}}, d_{\mathrm{c}}$, and $d_{\mathrm{s}}$.

\section{Discussion}

In search of the mechanism governing transport phenomena within the foam structure two different models were considered, namely developing laminar flow through a short capillary channel (called the flow-through model) and flow around a solid body (cylinder or sphere) (the flow-around model).

The flow-around model reflects the shape of the $C_{D}$ vs. $R e_{S}$ dependence very well. However, when based on the data collected for the three aluminum foams studied, neither flow around the infinite cylinder (representing the strut) nor the sphere show acceptable agreement with the experimental data. The drag coefficient $C_{\mathrm{D}}$ for the Al 10 PPI foam is distinctly lower than for the Al 20 PPI and Al 40 PPI ones. This cannot be explained by the foam porosity which is very close for all the three foams studied (cf. Table 1). Many different factors may influence the flow resistance, for example the cross-sectional shape of the struts or the roughness of the foam skeleton. For the Al 20 and 40 PPI foams, the cross-sectional shape of the struts is close to the regular triangle (with "sharp" vertices), but for the Al 10 PPI it is rather a spherical triangle. This shape can influence the drag coefficient 
and explain why the $C_{\mathrm{D}}$ coefficient for Al 10 PPI is lower than for other tested foams. Moreover, the thickness of the strut, as measured by the microscopy method, is in fact a distance between two edges, i.e., the side of the triangle. Because we model the strut as a cylinder of diameter $d_{c}$, thus the cross-sectional surface area is higher than for a triangle, i.e., higher than the real one. Furthermore, struts are randomly distributed within the foam space and the gas flow vector is perpendicular only to part of them; flow along the struts produces much lower drag forces. This is a possible explanation of the lower drag coefficient for the Al 10 PPI foam compared to the ideal infinite cylinder.

Both models (flow-through and flow-around) generally reflect the experimental behavior of the Fanning friction factor $\mathrm{f}$, or drag coefficient $C_{\mathrm{D}}$, vs. Reynolds number with different definitions of $D$ (cell diameter and strut thickness, respectively). Nevertheless, accuracies of the models differ slightly: for the flow-through model, an average error of about $25 \%$ was found while for the flow-around one the error reached $35 \%$, but the flow-through model seems to be the recommended approach reflecting the governing flow mechanism through the solid foams.

The above analysis shows the complexity of the fluid flow phenomena within the foam space. It is not easy to define a single mechanism governing the momentum transfer. Both the mechanisms (flow-through and flow-around) might exist simultaneously and only a more complex model might achieve higher accuracy.

\section{Materials and Methods}

\subsection{Foam Morphology}

The foams studied were aluminum foams $\mathrm{Al}$ 10, $\mathrm{Al} 20$ and Al 40 (ERG Materials and Aerospace Corp., Oakland, CA, USA) with pore density of 10, 20, and 40 PPI (pores per inch) according to the producer's specification [24].

Computer X-ray microtomography (SkyScan 1172, Bruker-microCT, Kontich, Belgium) and optical microscopy were applied to study the basic geometrical parameters of the foams. Microtomography imaged the foams' internal structure with a voxel size of $10 \mu \mathrm{m}$. The image processing was performed using the global thresholding method [25] assisted with iMorph software (v.2.8, available online [26]). The pore diameter, $d_{\mathrm{p}}$, was derived automatically from the microtomography and it represents both the foam cells and windows. Unfortunately, based on the microtomography results, it was difficult to distinguish between the cells and windows within the pore structure, thus optical microscopy was also applied. The microscopy results are based on about 100 measurements of either cell, window or strut dimensions. The basic geometrical parameters of the foams tested are presented in Table 1. The microtomography proved the foam skeleton is non-porous, as per the manufacturer's specification [24]. An exemplified tomography picture of the foam is presented in Figure 1 with the essential morphological elements and their dimensions noted.

\subsection{Flow Resistance Measurements}

The flow resistance experiments were carried out in a $0.057 \mathrm{~m}$ ID column filled with the foam studied. The foams were shaped as discs stacked up in the test column. Initial experiments did not indicate any influence of bed height on pressure drop so a single bed height of $0.3 \mathrm{~m}$ was applied. The experiments were performed using air at ambient pressure and temperature for gas velocities within $0.03 \div 1.8 \mathrm{~m} / \mathrm{s}$ for all the foams studied. The scheme of the experimental set-up is presented in Figure 5. 


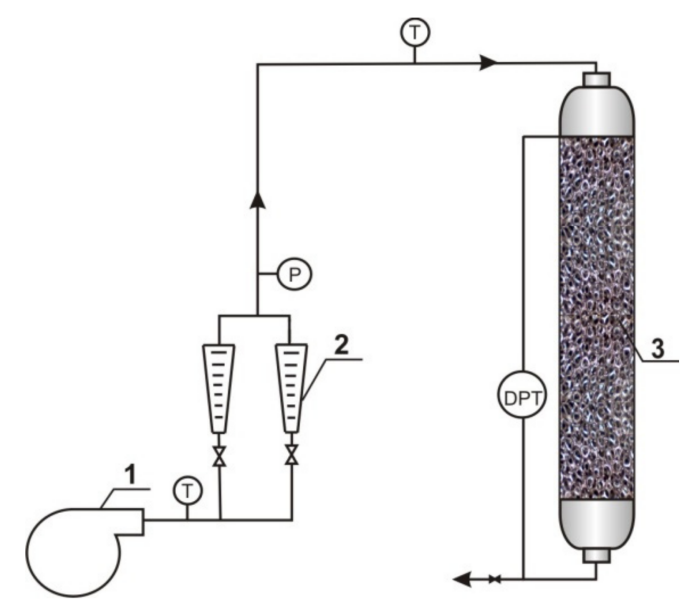

Figure 5. Experimental set-up: 1-blower; 2-gas flowmeters; 3-test column packed with the foams studied; T-temperature; $\mathrm{P}$ - pressure; DPT—differential pressure transmitter.

\section{Conclusions}

To determine the governing mechanism of fluid flow within the foam structure two models namely the flow-through mechanism (developing laminar flow in a short capillary channel) and the flow-around model (flow around an immersed solid body represented by infinite cylinder or sphere) were considered in this study. However, the models discussed here are based on theoretical considerations only that are valid for an ideal sphere or infinite cylinder (flow-around) or an ideal, short circular capillary channel (flow-through). This strongly limits the exactness of the models as their inaccuracies exceed $20 \%$.

While both the models reflect the experimental data, the accuracy of the flow-through one is better. However, the differences for both models are not so great as to settle the flow mechanism debate unequivocally. Foam structure is highly complex. Several morphological parameters may undoubtedly influence the flow mechanism and it is difficult to identify the dominant parameter. The so-called "secondary morphological parameters" such as strut cross-sectional shape (which is connected with foam porosity), node shape, and surface roughness may also influence the flow mechanism and thus flow resistance. All elements of the foam structure are rather far from the ideal geometrical shapes such as a sphere or an infinite cylinder. Furthermore, the struts forming the foam skeleton are randomly distributed in the foam space thus the flow direction is not perpendicular to all the struts. It seems a more accurate model should account for both the flow-around and flow-through mechanism and include the statistical distribution of the struts within the foam space.

Acknowledgments: The research was supported by the National Science Centre (Project No. DEC-2011/03/B/ST8/05455) and DEC-2016/21/B/ST8/00496.

Author Contributions: Jolanta Kowalska, Marzena Iwaniszyn and Joanna Łojewska conceived and designed the experiments and foam morphology tests, Marcin Piątek and Przemysław J. Jodłowski performed the experiments, Anna Gancarczyk and Andrzej Kołodziej developed the model presented and carried out the model from experimental data. All authors participated in the design of the study and assisted in drafting the manuscript. All authors read and approved the manuscript prior to submission.

Conflicts of Interest: The authors declare no conflict of interest.

\section{Appendix A}

Let us consider a very simplified foam model (Figure A1): in the foam volume $V$ the single cylinder (diameter $d_{\mathrm{s}}$ and length $l_{\mathrm{s}}$ ) represents the foam strut. The fluid flows with a superficial 
velocity $u_{0}$; as the strut is placed within the porous foam structure the approach velocity (to the model cylinder) is $u_{0} / \varepsilon$. The foam porosity is:

$$
\varepsilon=\frac{V-V_{\mathrm{s}}}{V}
$$

where $V$-overall is the volume of the foam sample and $V_{\mathrm{s}}$-solid is the volume for the case equal to

$$
V_{\mathrm{s}}=\frac{\pi d_{\mathrm{s}}^{2}}{4} l_{\mathrm{s}}
$$

The external strut (cylinder) specific surface area is

$$
S_{\mathrm{v}}=\frac{\pi d_{\mathrm{s}}}{V} l_{\mathrm{s}}
$$

and the frontal area is

$$
A=d_{\mathrm{s}} l_{\mathrm{s}}
$$

The drag force is defined as

$$
F_{\mathrm{D}}=C_{\mathrm{D}} \frac{\rho u_{0}^{2}}{2 \varepsilon^{2}} A
$$

that is

$$
F_{\mathrm{D}}=C_{\mathrm{D}} \frac{\rho u_{0}^{2}}{2 \varepsilon^{2}} l_{\mathrm{s}} d_{\mathrm{s}}
$$

and the pressure drop

$$
\frac{\Delta P}{L}=\frac{F_{\mathrm{D}}}{V}=C_{\mathrm{D}} \frac{\rho u_{0}^{2}}{2 \varepsilon^{2}} \frac{l_{\mathrm{s}} d_{\mathrm{s}}}{V}
$$

where $L$ is an edge of the cube of volume $V$ shown in the picture.

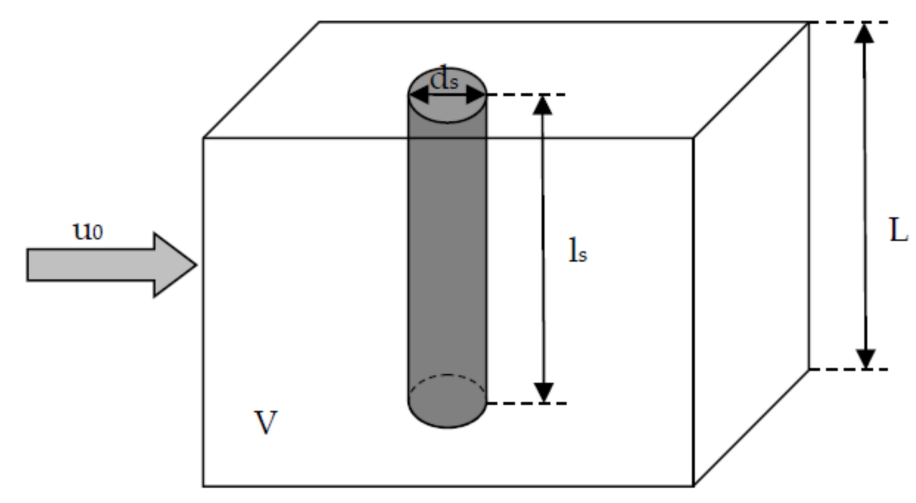

Figure A1. Simplified foam model designations.

Based on the picture above and Equations (A1) to (A3), the following relations can be written:

$$
\begin{aligned}
& 1-\varepsilon=\frac{\pi d_{\mathrm{s}}^{2} l_{\mathrm{s}}}{4 V} \\
& l_{\mathrm{S}}=\frac{S_{\mathrm{V}}^{2} V}{4 \pi(1-\varepsilon)} \\
& d_{\mathrm{S}}=\frac{4(1-\varepsilon)}{S_{\mathrm{V}}}
\end{aligned}
$$


Substituting in (A7) gives

$$
\frac{\Delta P}{L}=C_{\mathrm{D}} \frac{\rho u_{0}^{2}}{2 \pi \varepsilon^{2}} S_{\mathrm{v}}
$$

\section{References}

1. Edouard, D.; Lacroix, M.; Huu, C.P.; Luck, F. Pressure drop modeling on SOLID foam: State-of-the art correlation. Chem. Eng. J. 2008, 144, 299-311. [CrossRef]

2. Ochońska-Kryca, J.; Iwaniszyn, M.; Piątek, M.; Jodłowski, P.J.; Thomas, J.; Kołodziej, A.; Łojewska, J. Mass transport and kinetics in structured steel foam reactor with Cu-ZSM- 5 catalyst for SCR of $\mathrm{NO}_{x}$ with ammonia. Catal. Today 2013, 216, 135-141. [CrossRef]

3. Grosse, J.; Dietrich, B.; Garrido, G.I.; Habisreuther, P.; Zarzalis, N.; Martin, H.; Kind, M.; Kraushaar-Czarnetzki, B. Morphological characterization of ceramic sponges for applications in chemical engineering. Ind. Eng. Chem. Res. 2009, 48, 10395-10401.

4. Vicente, J.; Topin, F.; Daurelle, J.V. Open celled material structural properties measurement: From morphology to transport properties. Mater. Trans. 2006, 47, 2195-2202. [CrossRef]

5. Inayat, A.; Freund, H.; Zeiser, T.; Schwieger, W. Determining the specific surface area of ceramic foams: The tetrakaidecahedra model revisited. Chem. Eng. Sci. 2011, 66, 1179-1188. [CrossRef]

6. Garrido, G.I.; Patcas, F.C.; Lang, S.; Kraushaar-Czarnetzki, B. Mass transfer and pressure drop in ceramic foams: A description for different pore sizes and porosities. Chem. Eng. Sci. 2008, 63, 5202-5217. [CrossRef]

7. Buciuman, F.C.; Kraushaar-Czarnetzki, B. Ceramic foam monoliths as catalyst carriers. 1. Adjustment and description of the morphology. Ind. Eng. Chem. Res. 2003, 42, 1863-1869. [CrossRef]

8. Lucci, F.; Della Torre, A.; Montenegro, G.; Kaufmann, R.; Dimopoulos Eggenschwiler, P. Comparison of geometrical, momentum and mass transfer characteristics of real foams to Kelvin cell lattices for catalyst applications. Int. J. Heat Mass Transf. 2017, 108, 341-350. [CrossRef]

9. Bhattacharya, A.; Calmidi, V.V.; Mahajan, R.L. Thermophysical properties of high porosity metal foams. Int. J. Heat Mass Transf. 2002, 45, 1017-1031. [CrossRef]

10. Inayat, A.; Freund, H.; Schwab, A.; Zeiser, T.; Schwieger, W. Predicting the specific surface area and pressure drop of reticulated ceramic foams used as catalyst support. Adv. Eng. Mater. 2011, 13, 990-995. [CrossRef]

11. Giani, L.; Groppi, G.; Tronconi, E. Mass-transfer characterization of metallic foams as supports for structured catalysts. Ind. Eng. Chem. Res. 2005, 44, 4993-5002. [CrossRef]

12. Inayat, A.; Klumpp, M.; Lammermann, M.; Freund, H.; Schwieger, W. Development of a new pressure drop correlation for open-cell foams based completely on theoretical grounds: Taking into account strut shape and geometric tortuosity. Chem. Eng. J. 2016, 287, 704-719. [CrossRef]

13. Lacroix, M.; Nguyen, P.; Schweich, D.; Huu, C.P.; Savin-Poncet, S.; Edouard, D. Pressure drop measurements and modeling on SiC foams. Chem. Eng. Sci. 2007, 62, 3259-3267. [CrossRef]

14. Dietrich, B. Pressure drop correlation for ceramic and metal sponges. Chem. Eng. Sci. 2012, 74, 192-199. [CrossRef]

15. Richardson, J.T.; Peng, Y.; Remue, D. Properties of ceramic foam catalyst supports: Pressure drop. Appl. Catal. A 2000, 204, 19-32. [CrossRef]

16. Schlegel, A.; Benz, P.; Buser, S. Warmeubertragung und Druckabfall in keramischen Schaumstrukturen bei erzwungener Stromung. Warme- Und Stofffubertragung 1993, 28, 259-266. [CrossRef]

17. Almedeij, J. Drag coefficient of flow around a sphere: Matching asymptotically the wide trend. Powder Technol. 2008, 186, 218-223. [CrossRef]

18. Torobin, L.B.; Gauvin, W.H. Fundamental aspects of solids-gas flow: Part I: Introductory concepts and idealised sphere motion in viscous regime. Can. J. Chem. Eng. 1959, 37, 129-141. [CrossRef]

19. Tong, L.S.; London, A.L. Heat-transfer and flow-friction characteristics of woven-screen and crossed-rod matrixes. Trans. ASME 1957, 57, 1558-1570.

20. Iwaniszyn, M.; Ochonska, J.; Gancarczyk, A.; Jodlowski, P.; Knapik, A.; Lojewska, J.; Janowska-Renkas, E.; Kolodziej, A. Short-channel structured reactor as a catalytic afterburner. Top. Catal. 2013, 56, 273-278. [CrossRef]

21. Shah, R.K. A correlation for laminar hydrodynamic entry length solutions for circular and noncircular ducts. J. Fluids Eng. 1978, 100, 177. [CrossRef] 
22. Shah, R.K.; London, A.L. Laminar Flow Forced Convection in Ducts: A Source Book for Compact Heat Exchanger Analytical Data; Academic Press: New York, NY, USA, 1978.

23. Kolodziej, A.; Lojewska, J.; Jaroszynski, M.; Gancarczyk, A.; Jodlowski, P. Heat transfer and flow resistance for stacked wire gauzes: Experiments and modelling. Int. J. Heat Fluid Flow 2012, 33, 101-108. [CrossRef]

24. ERG Materials and Aerospace Corp. Available online: http://www.ergaerospace.com (accessed on 6 February 2017).

25. Leszczyński, B.; Gancarczyk, A.; Wróbel, A.; Piątek, M.; Łojewska, J.; Kołodziej, A.; Pędrys, R. Global and local thresholding methods applied to X-ray microtomographic analysis of metallic foams. J. Nondestruct. Eval. 2016. [CrossRef]

26. iMorph Software. Available online: http://imorph.fr (accessed on 6 February 2017).

(C) 2017 by the authors. Licensee MDPI, Basel, Switzerland. This article is an open access article distributed under the terms and conditions of the Creative Commons Attribution (CC BY) license (http://creativecommons.org/licenses/by/4.0/). 